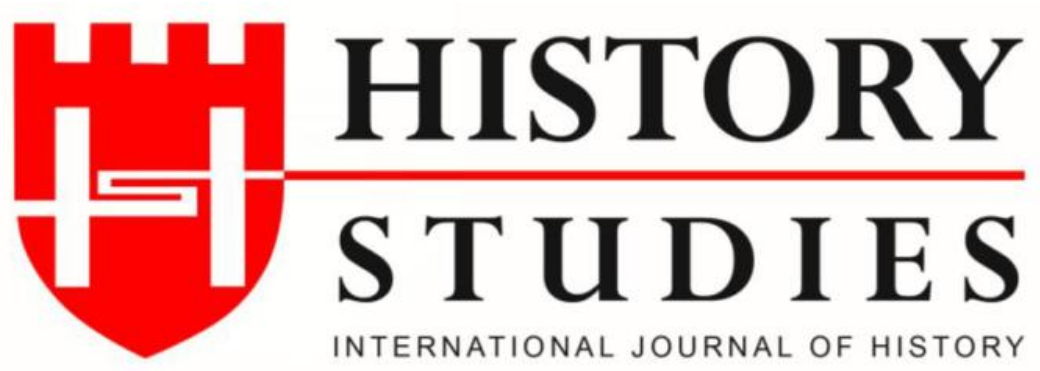

ISSN: 13094173 (Online) 1309 - 4688 (Print)

Volume 12 Issue 2, A Tribute to Assoc. Prof. Dr. İlknur Mangir Karagöz, April 2020

DOI Number: 10.9737/hist.2020.837

Araştırma Makalesi

Makalenin Geliş Tarihi: 13.12.2019 Kabul Tarihi: 29.02.2020

Atıf Künyesi: Yıldız Deveci Bozkuş, “Osmanlı Modernleşmesinde Ermeni Bir Entelektüel: Hukukçu

Orhan Vahan”, History Studies, Doç. Dr. İlknur Mangır Karagöz Armağanı, 12/2, Nisan 2020,

s. 413-426.

\title{
Osmanlı Modernleşmesinde Ermeni Bir Entelektüel: Hukukçu Orhan Vahan ${ }^{1}$
}

\author{
Armenian Intellectuals in Ottoman Modernization: \\ The Example of Lawyer Orhan Vahan \\ Doç. Dr. Yıldız Deveci Bozkuş \\ ORCID No: 0000-0002-4634-463X \\ Ankara Yıldırım Beyazıt Üniversitesi
}

Volume 12

Issue 2

A Tribute to

Assoc. Prof.

Dr. İlknur

Mangir

Karagöz,

April

2020
Öz: Bu çalışmada Osmanlı modernleşme sürecinde Ermeni entelijansiyanın önemli isimlerinden biri olan Orhan Vahan'ın hayatı ve eserleri ele alınacaktır. Osmanlı İmparatorluğu'nda Ermeniler birçok alanda Osmanlıca eserler kaleme almışlardır. Bu alanlar arasında filoloji, mimari, tıp, kimya, hukuk, iktisat, edebiyat, sanat vb. alanlar ilk sırada yer almaktadır. Osmanlı İmparatorluğu'nda modernleşme dönemi aydınlarından biri olan Orhan Vahan da söz konusu dönemde hukuk alnında çok sayıda eser kaleme almış önemli bir Ermeni entelektüeldir. Bu çalışmada Orhan Vahan'ın eserlerinden hareketle Osmanlıca kaleme aldığı çalışmalarının Türk modernleşme sürecine sunduğu katkılar incelenecektir. 1832 yılında İstanbul, Ortaköy'de dünyaya gelen Orhan Vahan, Hovhannes/Ohannes Sarkis Vahanyan ve Ohan Vahan olarak da bilinmektedir. Çağdaşı olan Kirkor Zohrab, Diran Kelekyan, Nadret Haçeryan, Viçen Hukukçiyan gibi isimlerle birlikte modernleşme döneminde hukuk alanında öne çıkan Orhan Vahan ticaret ve hukuk alanında oldukça kapsamlı eserler kaleme almıştır.

Anahtar Kelimeler: Osmanlı, Modernleşme, Ermeni, Orhan Vahan, Entelektüel.

Abstract: In this study, the life and works of Orhan Vahan, one of the important names of the Armenian intelligentsia in the Ottoman modernization process, will be discussed. In the Ottoman Empire, Armenians wrote Ottoman works in many areas. These fields include philology, architecture, medicine, chemistry, law, economics, literature, art, etc. areas are in the first place. Orhan Vahan, one of the intellectuals of the modernization period in the Ottoman Empire, was an important Armenian intellectual who wrote many works in the field of law in that period. In this study, the contributions of the works written by Orhan Vahan in Ottoman Turkish to the Turkish modernization process will be examined. Orhan Vahan, who was born in Istanbul, Ortaköy in 1832, is also known as Hovhannes / Ohannes Sarkis Vahanyan and Ohan Vahan. Orhan Vahan, who became prominent in the field of law during the modernization period with his contemporary Kirkor Zohrab, Diran Kelekyan, Nadret Haçeryan, Viçen Hukukçiyan, wrote quite extensive works in the field of trade and law.

Keywords: Ottoman, Modernity, Armenian, Orhan Vahan, Intellectual.

${ }^{1}$ Bu çalışma TÜBİTAK 2219-Yurt Dışı Doktora Sonrası Araştırma Burs Programı kapsamında desteklenmiştir. Tübitak'a desteği için teşekkür ederiz. 


\section{Giriş:}

Anadolu'nun fethedilmesiyle birlikte Ermeniler, beraber yaşamaya başladıkları Osmanlı toplumuna çeşitli alanlarda pek çok katkı sunmuş, çalışkan, azimli, yetenekli ve bir o kadar da toplumla iç içe geçmeyi başarmış tarihteki ender topluluklardan biri olmuştur. $\mathrm{Bu}$ nedenle günümüzde Türk-Ermeni ilişkilerinde 1915 Olayları iki toplum arasında bir kırılma noktası olarak görünse de iki toplum arasındaki tarihsel geçmişin ayrıca detaylı bir şekilde incelenmesi ve gün yüzüne çıkarılması gerekmektedir. Ancak ne yazıkki günümüzde popüler kültür ve popüler tarihin de etkisiyle gerek Türkiye'ye gerekse Ermenistan'a ve uluslarararası literature bakıldığında iki toplum arasındaki bin yıllık geçmişten ziyade 1915 odaklı çalışmaların sayısının çok daha fazla olduğu görülmektedir. Tam da bu noktada 1915 öncesi Ermeni entellektüelllerinin Osmanlı toplumundaki yeri ve ürettikleri eserler incelenmeden yapılacak çalışmalar bir yanıyla daima eksik kalacaktır. Bu eserlerin incelenmesi başta Türk toplumu olmak üzere hem Ermeni, hem de diğer etnik gruplar açısından oldukça önemlidir. Nitekim Osmanlı'nın son dönemlerindeki siyasi, tarihi, ekonomik ve politik yapılara dair bilgi sunan yegane kaynaklar arasında söz konusu dönemde Ermeni entellektüellerinin ürettikleri eserlerin de önemli bir yeri olduğunu belirtmek gerekir.

Osmanlı modernleşme hareketleri açısından XIX. Yüzyıl önemli bir dönem olmuştur. $\mathrm{Bu}$ süreçte Batıdaki bir çok gelişme toplumdaki farklı dini ve etnik gruplara mensup entellektüeller aracılığıyla topluma aktarılmıştır. Bu aktarım sırasında Türk entellektüellerin rolü kadar Ermeni entellektüellerinin de bu sürece ciddi bir katk1 sundukları görülmektedir. Edebi, kültürel, sanatsal, hukuksal ve daha bir çok konuda Ermeni entellektüelleri bazen öncü görevinde bazen de topluma uygulama noktasında rol almışlardır. Osmanlı İmparatorluğu'nda yaşayan entellektüel sınıfının Batıdaki gelişmeleri ve yenilikleri Türk toplumuna aktarmak için bazı kurum ve kuruluşlar oluşturdukları da bilinmektedir. Bunlardan biri de Batıdaki bilim ve kültürü Osmanlıda yaymak için kurulan Cemiyyet-i Ilmiyye-i Osmaniyye olmuştur. Batıdaki pozitif bilimlerin ve fen alanındaki gelişmelerin Osmanlı'da yaygınlaştırılmasını amaçlayan bu cemiyetin kurucuları arasındaki 33 kişiden 9'u Ermenilerden oluşmuştur. ${ }^{2}$ Bu husus Osmanlı modernleşme sürecinde Türk entellektüel sınınıfının yanı sıra diğer etnik grupların da sürece dahil olduklarını göstermesi açısından önemlidir. Bunların yanısıra Osmanlı İmparatorluğu döneminde Ermeni entelektüellerinin yayınlarının da modernleşme sürecinde katkıları olmuştur. Bu yayınlardan biri olan Mehyan (Pagan Tapınăğ) adlı derginin de modernleşme sürecinde entellektüeller arasında önemli bir yeri vardır. Hagop Oshagan (1883-1948), Kegham Parseghian (1883-1915) ve Gosdan/ Kostan Zarian tarafından yayınlanan Mehyan bazı araştırmacılar tarafından modernist bir deneme olarak da adlandırılmıştır. Mehyan'da ayrıca Taniel Varujan (1884-1915)'ın da çeşitli yazıları yer almıştır. ${ }^{3}$ Söz konusu Ermeni entellektüeller, dönemin romantik, realist ve radikal entellektüelleri olarak adlandırılmışlardır. Özellikle ve sekülarist modernleşme ve aydınlanma, siyasi reformlar ve demokratikleşme

\footnotetext{
${ }^{2}$ Ali Budak, "Ermeniler'in XIX. Yüzyılda Yeni Bir Hayatın ve Edebiyatın Oluşum Sürecine Katkıları”, Journal of Academic Studies, Y1l: 8, Sayı: 30 Ağustos - Ekim 2006, s.156.

${ }^{3}$ Hülya Adak, "Literature (Ottoman Empire)", International Encyclopedia of the First World War,https://encyclopedia.1914-1918-online.net/article/literature_ottoman_empire\#GND_142175331 (E.T.11.12.2018)
}

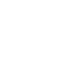


konularında ciddi etkileri olmuş, ulusal kurtuluş ve sosyal, kültürel serbestleşme konularını tartışmaya açmış entellektüeller olmuşlardır. ${ }^{4}$ Bu hususta George Washburn, Robert Koleji 'in İlk Müdürü, Cennetin Sonbaharı adlı eserinde aklı başında olan Ermeni aydınlarının Ermeni devrimcilerle işbirliği yapmadığını ve onlara hiç de sempati beslemediklerine dikkat çeker. Ermeni aydınlarının aslında ülkenin her yanına yayılmış halkarının ümitlerini başkaldırarak değil asıl aydınlanmanın barış̧̧ı girşimlerle gerçekleşebileceğinin farkında olduklarına dikkat çekerek sırf bu nedenlerle çok sayıda Ermeni entellektüel ailenin çocuklarını Robert Koleji’ne gönderdiğini dahi ifade eder. ${ }^{5}$

Ermeni entellektüellerinin İstanbul merkezli ancak Avrupa eğitimli olduğunu kaydeden Panossian'a göre ise, bu entellektüellerin çoğu Mikhitar okullarında okuyarak kariyerlerine başlamışlardır. Bu nedenle Mıkhitar okullarının Ermeni entellektüel dünyasının oluşumunda önemli bir yeri bulunmaktadır. Özellikle 1825-1850 yılları arasında hem klasik hem de modern olmak üzere Avrupa edebiyatına dair 130 ciltlik bir külliyatın Ermeniceye tercüme edildiğine dikkat çeken Panossian, bir süre sonra bu tür eserlerin basımına İstanbul ve İzmir'de de başlandığına, buralarda Fransızca, İtalyanca ve İngilizce eserlerin de tercüme edildiğine de işaret etmiştir. ${ }^{6}$ Benzer şekilde Vahe Oshagan ise 1843-1848 yılları arasında İstanbul'daki okullardan en parlak 31 Ermeni öğrencinin seçilerek Batılı bir eğitim almaları için Avrupa'ya gönderildiğini kaydetmiştir. Özellikle Avrupa'ya ve Fransa'daki üniversitelerde eğitilmek üzere Batıya gönderilen bu öğrencilerin İstanbul'a döndüklerinde modernizasyonun bir parças1 olan okullar açtıklarını, basın yayın faaliyetlerinde bulunduklarını, dil ve anayasal çalışmaların hazırlanmasına katkıda bulunduklarına işaret edilmiştir. 1850'li yıllar kuşağındaki Ermeni entellektüellerin çılgınca Batılı yazarların eserlerini de çevirmeye başladığını kaydeden Oshagan, entellektüellerin Batılı klasikleri çevirdiklerini, bu klasiklerden özellikle Fransız yazarlara büyük bir ağırlık verdiklerini belirtir. $\mathrm{Bu}$ yazarlar arasında Lamartine, Hugo ve Chateaubriand gibi yazarların ayrı bir yeri olduğunu belirten Oshagan, entellektüellerin böylelikle batılı yazarların düşüncelerini de topluma aktardığını kaydeder. ${ }^{7}$ Oshagan'a göre XVIII yüzyıl Mıkhitaristleri aynı zamanda Avrupanın klasik ve romantizm öncesi yazarları olan Chateaubriand, Bernardin de Saint Pierre, Edmond Young ve Fenelon gibi edebiyatta iyi ve öğretici olan ve ruhban sınıfına da karşı olmayan yazarlarından da etkilenmişlerdir. ${ }^{8}$ Zekiyan'a göre Ermenilerin Batı dünyasıyla kurduğu yakın temas beraberinde Ermenilerin Batı dünyasının modernite sürecine asimilasyonlarını da hızlandırmıştır. ${ }^{9}$

\footnotetext{
${ }^{4}$ Armenian Constantinople, Mazda Publishers, Editör: Richard G. Hovannisian, S. Payaslian USA 2010, s.3.

${ }^{5}$ George Washburn Robert Koleji' in Illk Müdürü, Cennetin Sonbaharı, Kolej Anıları 1863-1903, Atlantis Yayınları, İstanbul 2002, s.272.

${ }^{6}$ Razmik Panossian, The Armenians, From Kings and Priests to Merchants and Commissars, Columbia University Press, New York 2006, s.138-139.

${ }^{7}$ Vahe Oshagan, "From Enlightenment to Renaissance: The Armenian Experience", Edt: Richard G. Hovannisian and David N. Myers, Enlightenment and Diaspora, The Armenian and Jewish Cases, Scholor Press, Atlanta, Georgia 1999, s.159.

${ }^{8}$ Agm,s.163.

9 Boghos Levin Zekiyan, "Christianity to Modernity”, Edt: Edmund Herzig and Marina Kurkchiyan, The Armenians, Past and Present in the Making of National Identity, RoutledgeCurzon, London 2005, s.60-61.
} 
Osmanlı İmparatorluğu bürokrasisinde bulunan Ermenilerin birçoğu oldukça donanımlı ve çok yönlü Ermeni entellektüel sınıfından oluşmaktadır. ${ }^{10}$ Bu konuda Zeidner, Ermenilerin Osmanlı Devleti içerisindeki resmi hizmetlerin üçte birini oluşturduklarına dahi işaret eder. ${ }^{11}$

Ermeni entellektüellerin Türkçe'ye yaptıkları çevirilerin bir bakıma Batılı ülkeleri tanıma noktasında da etkili olduğu görülmektedir. Batıdaki eşitlik, özgürlük, adalet, eğitim, sosyal ve kültürel gelişmeler bu çalışmalar aracıllı̆̆yla ülkeye getirildiğinden, bu tür eserler adeta bir köprü vazifesi görmüştür.

Bu köprüyü kuranlardan biri de Orhan Vahan'dır. Bu anlamda Vahan, Ermeni kökenli entellektüel sınıfına mensup hukukçi kimliğiyle oldukça dikkat çeken bir şahsiyet olmuştur.

\section{Orhan Vahan'm Hayatı ve Eserleri:}

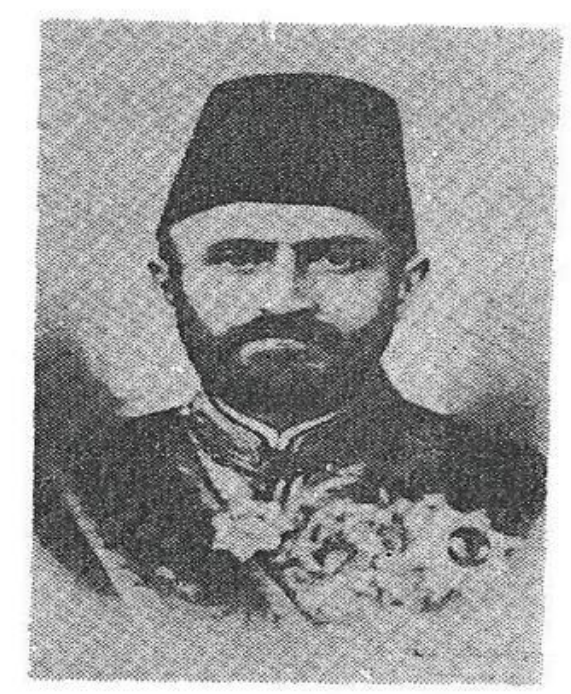

Resim 1:Z. [ZnlhuGGGitu] U. [Uupqhu] Y.U.ZU.४BU. 12

\begin{tabular}{|c|}
\hline $\begin{array}{l}\text { HISTORY } \\
\text { STUDIES }\end{array}$ \\
\hline 416 \\
\hline Volume 12 \\
\hline $\begin{array}{c}\text { Issue } 2 \\
\text { A Tribute to }\end{array}$ \\
\hline Assoc. Prof \\
\hline Dr. Ilknur \\
\hline Mangir \\
\hline $\begin{array}{c}\text { Karagöz, } \\
\text { April }\end{array}$ \\
\hline 2020 \\
\hline
\end{tabular}

Orhan Vahan ${ }^{13}$

Sarkis adında bir amira sınıfına mensup tüccarın oğlu olarak 1832 yılında İstanbul Ortaköy'de dünyaya gelen Orhan Vahan; Vahan Efendi, Hovhannes/Ohannes Sarkis Vahanyan,

\footnotetext{
${ }^{10}$ Robert F. Zeidner, "Britain and the Launching of the Armenian Question", International Journal of Middle East Studies, 7(4), 1976, s.469, M.Sadi Koçaş, Tarihte Ermeniler ve Türk-Ermeni İlişkileri, Kastaş Yayınları, İstanbul 1990, s.108-130, Mesrob K. Krikorian, Armenians in the Service of the Ottoman Empire: 1860-1908, Routledge \& Kegan Paul, London 1977, s.102-110. Bu konuda detaly bilgi için bkz: Hratch Kouyoumjian, Ethnic Armenian Civil Servants in the Ottoman Empire in 1909, Armenian Genocide Centenary Commemoration Committee Pub., Great Britain, 2015, s.8-57.

${ }^{11}$ Zeidner, agm, s. 469.

${ }^{12}$ Orhan Vahan'ın ismi bazı kaynaklarda Vahan Efendi, Hovhannes/Ohannes Sarkis Vahanyan, Ohan Vahan şeklinde de geçtiği tespit edilmiştir. İngilizce kaynaklarda ise 'Wahan' olarak yazıldığı görülmektedir. Şeref Etker, "Vahan Efendi (H.S. Vahanyan) ve Kimya Biliminin Temel İlkeleri”, Osmanlı Bilimi Araştırmaları XIII/2 (2012), s.41-64.

${ }^{13}$ Tomas Terziyan, "Ermenice İlk Kimya Kitabının Yazarı Hovhannes Sarkis Vahanyan'ın Hikâyesi", Hyetert,https://hyetert.org/2018/02/01/ermenice-ilk-kimya-kitabinin-yazari-hovhannes-sarkis-vahanyaninhikayesi/(E.T.12.08.2019).
} 
Ohan Vahan olarak da bilinmektedir. 25 Nisan 1891'de İstanbul, Taksim'de hayatını kaybeden Orhan Vahan' ${ }^{14}{ }^{14}$ annesi Nazlı Vahanyan, Kayserili, kökenleri amira Arzumanyanlara dayanan, birkaç dile hakim, hayrıseverliğiyle bilien bir kadındır. ${ }^{15}$ Vahan Efendi'nin ailesinin kökenlerine dair çok fazla bilgi olmasa da Orhan Vahan'ın Sırpuhi adında bir kız kardeşi olduğu bilinmektedir. Vahan'ın ise Astine Vahan-Serviçen ve Araksi Vahan Gülbenkyan adında iki kızı olduğu kaydedilmiştir. ${ }^{16}$

1848 yılında ailesi tarafından Paris'e gönderilen Vahan, Tomas Terziyan'ın ifadesiyle daha gençlik yıllarından itibaren tabiat ilmine tutkun bir gençtir. Paris’te eğitimine devam ederken Dr. Nahabed Rusinyan, geleceğin ünlü edebiyatçısı Dr. Hovsep Şişmanyan ve diğer Ermeni entellektüellerle bir araya gelme ve tanışma fırsatı yakalayan Vahan'ın buradaki Genç

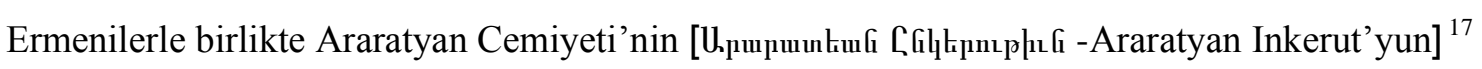
faaliyetlerine katılmıştır. ${ }^{18}$

Paris'te dört y1l boyunca eğitim alan Vahan Efendi, 1852 y1lında İstanbul'a kimyager olarak geri dönmüştür. Henüz 24 yaşındayken devlet hizmetinde görev almaya başlayan Vahan Efendi, 1865 y1lında Tercüme Cemiyeti'nin kuruluşunda üye olarak görev almıştır. Bir dönem Ahmet Cevdet Paşa'ya danışmanlık da yapmış olan Vahan Efendi, Ticaret Mahkemeleri üyeliği ve 1868 'de Divan-1 Ahkam-1 Adliye ve 1871 'de Şura-yı Devlet azası görevlerinde de bulunmuştur. ${ }^{19}$

Etker'in Vahan Efendiyle ilgili olarak kaleme aldığı kapsamlı çalışmasında Vahan

Volume 12

Issue 2

A Tribute

to Assoc.

Prof. Dr.

İlknur

Mangir

Karagöz,

April

2020 Efendi'nin 1872'li yıllarda Maarif Nazırı olan Kimyager Derviş Mehmet Emin Paşa'nın müsteşarlığı görevini de yerine getirdiği ifade edilmiştir. Vahan Efendi’nin ayrıca Nafia Nezareti Müsteşarı ve Islahat Komisyonu üyeliği görevlerinde de bulunduğu belirtilmektedir. Bunların yanı sıra Adliye Nezareti Müsteşarlığı ve Mekteb-i Sultani’ye (Galatasaray Lisesi) müdür olarak görevlendirildiği, Adliye Nezareti Müsteşarlığında 'bâlâ' rütbesiyle hizmet ettiğini, Birinci Meşrutiyet'te (1876) Kanun-i Esasi Komisyonu üyeliği görevlerinde de aktif olarak rol aldığı kaydedilmiştir. Etker'in vahan Efendiyle ilgili son derece değerli çalışmasında ayrıca Vahan Efendi'nin Defterhane (Defter-i Hakani) Nezareti'nde bulunduğu, 1877 yılında ise Selanik'te çıkan olayları soruşturmakla görevlendirildiği de ileri sürülmüştür. Tüm bu son derece önemli ve üst düzey görevlerin yanı sıra Vahan Efendi'nin Batı'daki yargı sistemlerini incelemesi ve bu konularda bilgi edinmesi amaciyla Avrupa'ya gönderildiğini kaydeden

\footnotetext{
${ }^{14}$ Bazı kaynaklarda doğum tarihi 1835 olarak geçmektedir. Abdülhamit Kırmızı, "European Educational Backgrounds of Armenian Officials in the Ottoman Empire", Editör: Andreas Schmoller, Middle Eastern Christians and Europe: Historical Legacies and Present Challenges, LIT, Zurich 2018, s.71, dipnot 62.

${ }^{15}$ Terziyan, agm, ss.41-64.

16 Yıldız Deveci Bozkuş, “An Important Armenian Female Writer Prominent in the Ottoman Period: Srpuhi Dussap”, IASSR, 2017, (E.T.11.06.2018).

${ }^{17}$ Genç Ermeniler tarafindan Paris'te 27 Nisan 1849'da kurulan bu dernek Paris'te bulunan tüm Ermeni gençlerinin bir araya geldiği, herhangi bir mezhep ya da politik örgüt bağlantısı olmayan Ermeni Katolik öğrencilerin de toplandığı bir kuruluştu. Burada başta Ermeni halkının eğitimi olmak üzere Ermeni dilinde, okullarında ve merkezi idarede reform konularında adımlar atılması vb. konulara yer verilmekteydi. Vartan Artinian, Osmanlı Devleti'nde Ermeni Anayasası'nın Doğuşu 1839-1863, Çev: Zülal Kılıç, Aras Yay., İstanbul 2004, s.77-78.

${ }^{18}$ Terziyan, agm, ss.41-64.

${ }^{19}$ Etker, agm, ss.42-62.
} 
Etker'e göre, Vahan Efendi Kumkapı Ermeni Patrikhanesi'nde 1890'da çıkan olaylar sırasında ise bu olayların incelenmesi konusunda da görevlendirilmiştir. ${ }^{20}$

Orhan Vahan'la ilgili diğer bir önemli husus ise, Ermeni edebiyatının önemli kadın yazar ve kadın entellektüellerinden olan Sırpuhi Düsap'ın ${ }^{21}$ da (Dussap-Vahanyan, 1841-1901) kendisinin kızkardeşi olmasıdır. ${ }^{22}$

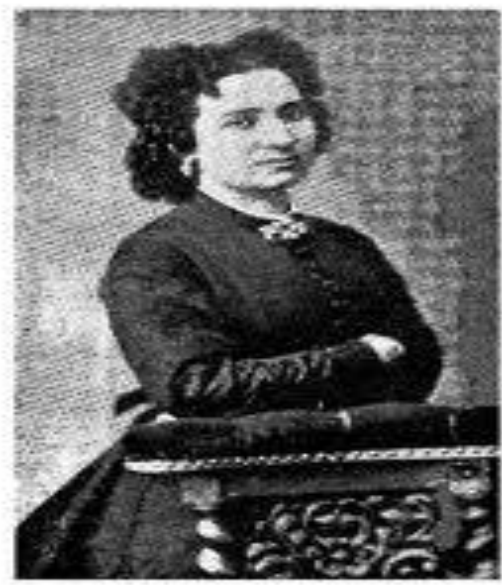

Resim 2: Sırpuhi Vahanyan-Düssap (Ortaköy, İstanbul, 1841-16 Ocak 1901),

$\mathrm{U}_{\text {ppnıhl }}$ Shıuшp, Srpouhi Dussap ${ }^{23}$

Düssap'ın ${ }^{24}$ adı zaman zaman Osmanlı İmparatorluğu döneminde kimya biliminde önemli çalışmalara imza atmış olan Vahan Efendi’nin kız kardeşi olarak da anılmaktadır.

\footnotetext{
${ }^{20}$ Etker, agm, s.42.

${ }^{21} 1841$ 'de İstanbul'da dünyaya gelen Sırpuhi Düsap, Ermeni Edebiyatı ve Ermeni kadın yazarları arasında önemli bir yere sahiptir. Düsap, bilinen ilk Ermenice yazan kadın romancı olmasının yanı sıra Ermenice deneme, makale ve çeşitli romanlarda, kadınların yaşam modellerini ele almış önemli bir aydındır. Osmanlı İmparatorluğu döneminde modernleşme hareketlerinin başta edebiyat olmak üzere bir çok alanda etkisini gösterdiği bir süreçte Düsap, Avrupa'daki kadın örgütlerinin "eşitlik" tartışmalarını yakından takip etmiştir. Batı dünyasında ortaya çıkan modernleşmenin de etkisiyle Düsap, Osmanlı İmparatorluğunda yaşayan kadınların içinde bulunduğu durumu konu edinen eserler kaleme almaya başlamıştır. Kaleme aldığı eserlerde genellikle kadın ve kadının toplumdaki yeri üzerinde durarak bu konuda toplumsal duyarlılık yaratmaya çalışmıştır. Yaşadığı dönem içinde oldukça iyi bir eğitim seviyesine sahip olan Düsap, çeşitli okullar açmış, gazete, dergi ve piyeslerin hazırlanmasında görev almıştır. Eserlerindeki karakterlere genel olarak bakıldığında Düsap'ın eğitimli, orta ve üst sınıf kadınların karşılaştığı sorunlara odaklandığ 1 görülür. Kaleme aldığı eserler hem kendi dönemi hem de kendinden sonraki süreçte Ermeni kadın yazarlar açısından yol gösterici bir etkiye sahip olmuştur. Bu yazarlar arasında Sibil, Zabel Yesayan ve Arşaguhi Teotig gibi yazarlar ilk sırada gelir. Detaylı bilgi için bkz: Deveci Bozkuş, agm.

${ }^{22}$ Etker, agm, s.43.

23“"Sirpuhi Düsap ilk feminist Ermeni kadın romancıdır", http://akunq.net/tr/?p=22140 (E.T.03.05.2016)
}

\section{History Studies}

Volume 12

Issue 2

A Tribute to

Assoc. Prof.

Dr. İlknur

Mangir

Karagöz,

April

2020 
Araştırmacılar tarafından ağabeyi Vahan Efendi'nin nekroloji yazdığı da kaydedilen Düssap'ın ailesinin ${ }^{25}$ varlıklı bir aileden geldiği ve özellikle Düssap'ın bir yazar olarak yetişmesinde annesi Nazlı Vahan'ın (1814-1884) son derece önemli ve etkili ayrı bir yeri olduğu da kaydedilmiştir. $^{26}$

Yaşadığı dönem içerisinde seçkin ve varlıklı bir aile olarak öne çıkan Düssap'ın ailesi， tıpkı Vahan Efendi gibi yazarın Düssap'ın da Batı eğitimi, özellikle de Fransız kültürüne aşina olmasında ciddi katkı sağlamıştır. Düssap ve Vahan Efendinin babası Sargis Vahanyan'dır. ${ }^{27}$ Vahan'ın babası Sarkis Efendi 1842 yılında vefat etmiştir, bu tarihlerde Sırpuhi henüz bir, ağabeyi Vahan'ın ise daha on yaşında olduğunu ve Sırpuhi'nin tabiat bilgisi ve tarih eğitimini ağabeyi Vahan'dan aldığını kaydeden Terziyan, Vahan'ın daha sonra Dadyanların kızı Nazik Hanımla evlendiğini ve iki kızı olduğunu kaydeder. ${ }^{28}$

Katolik bir ailede dünyaya gelen Düssap ve Vahan Efendi, kendi eğitiminin yanı sıra kadınların eğitimi konusunda da çeşitli faaliyetlerde bulunmuş, Düssap 1859 yılında Hripsimyants Okulu'nun açılması konusunda, ileri gelen Ermeni feminist kadınlarla ortak hareket etmiştir. ${ }^{29}$ Düssap'ın annesi Nazlı Vahan, yaşadığı dönemde Ermeni cemaati içinde kız çocuklarının okumasına büyük önem veren varlıklı bir amira sınıfından gelmekteydi. ${ }^{30}$

Vahan Effendi gibi Düssap'ın da yazar ve entellektüel olarak yetişmesinde anne Nazlı Vahan'ın çocuklarını etkin ve bilinçli yetiştirmesi nedeniyle, çocuklarının çok genç yaşta toplumsal hayat hakkında fikir sahibi olmalarına ve kendini sarmalayan entelektüel çevrenin etkisiyle belli değerler edinip olgunlaşmaya başlamışlardır. ${ }^{31}$

Volume 12

Issue 2

A Tribute

to Assoc.

Prof. Dr.

İlknur

Mangir

Karagöz,

\footnotetext{
24 Ortaköylü Ohannes Vahanyan, İstanbul'da eğitimini tamamlandıktan sonra, ailesi tarafından kimya eğitimi görmesi için Fransa'ya gönderildi. Dört yıllık öğreniminin ardından 'kimyager' olarak Türkiye'ye dönen Vahanyan'ın, Kalem'e alınıp Osmanlı bürokrasi kadrosuna girmesiyle yaşamı bütünüyle değişecektir. Vahan Efendi, artık değişik devlet dairelerinde, kurullarında ve nezaretlerde kariyer sahibi olacaktır... Vahan Efendi'nin adını kimya bilimi ile özdeşleştiren, İstanbul'a dönüşünde 1853'te yayımladığ Ermenice kitabı Kimya Biliminin Temel İlkeleri / Isgızpunk Kimiagan Kidutyan olmuştur. Bu kitap, Henri-Victor Regnault'nun Premiers éléments de chimie adlı kitabının ilk (1850) baskısının bir çevirisidir ve Vahan Efendi'nin kitabı Ermeni dilindeki ilk kimya kitabıdır. Etker, agm, s.43-62.

${ }^{25}$ Agm, s.62.

${ }^{26}$ Victoria Rowe, A History Of Ermenian Womens Writing: 1880 - 1922, Cambridge Scholars Press, İngiltere 2003. s.36.

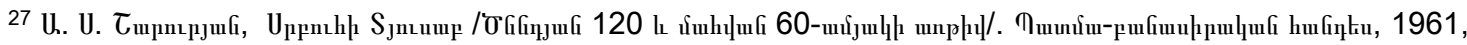
(A. S. Şaruryan, Sırpuhi Düssap /Tzndyan 120 yev Mahvan 60-amyaki ar'tiv, Patma-banasirakan handes), N 3-4 . ss. 166-180.

${ }^{28}$ Terzian, a.g.m.

${ }^{29}$ Markar Eseyan, 20. Yüzyıla Girerken Ermeni Edebiyatında Modernite, Yeni Burjuvazi ve Sinıfsal Çatışmalar, (İstanbul Bigi Üniversitesi, Sosyal Bilimler Enstitüsü, Kültürel Çalışmalar Yayınlanmamış Yüksek Lisans Tezi), İstanbul 2010, s.111.

${ }^{30}$ Maral Aktokmakyan, "Sırpuhi Düsap: Ermeni Kadın Edebiyatının

Başlangıcı"http://www.arasyayincilik.com/tr/basindan/sirpuhi-dusap-ermeni-kadin-edebiyatinin-baslangici/149

(E.T.01.03.2009)

${ }^{31}$ Maral Aktokmakyan, "Sırpuhi Düsap: Ermeni Kadın Edebiyatının

Başlangıcı" http://www.arasyayincilik.com/tr/basindan/sirpuhi-dusap-ermeni-kadin-edebiyatinin-baslangici/149

(E.T.01.03.2009)
} 


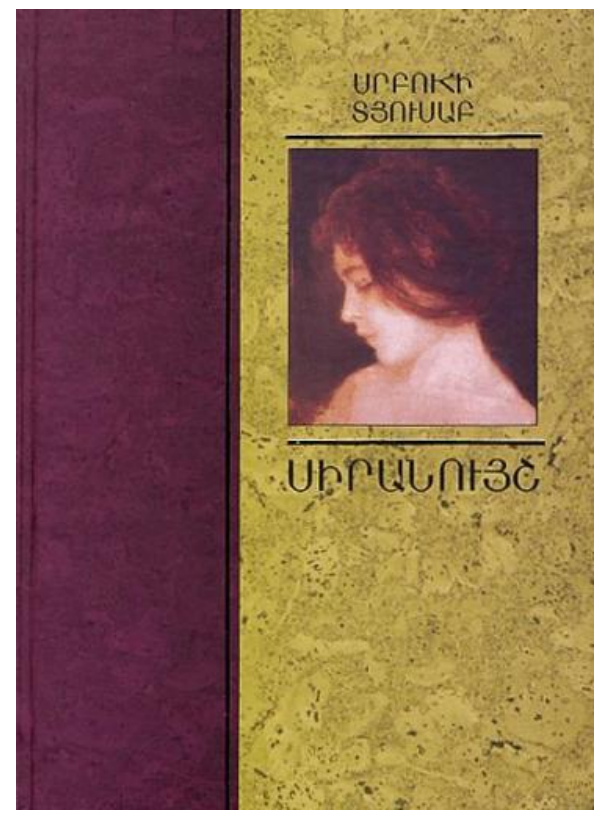

Resim 3: Sırpuhi Düssap'ın Siranuş Adlı Eserinin Kapağı 12

Görüldüğ̈ gibi Düssap'ın ve abisi Vahan Efendi'nin entellektüel dünyasının oluşumu ve şekillenmesinde en büyük pay anne Nazlı Vahan'a aittir. Nazlı Vahan'ın dünyaya bakış açısı kızı Düssap'ın ve oğlu Vahan Efendi'nin de dünyasını etkilemiş ve bu yolda genç yaşta hızlı bir yol almalarının önünü açmıştır.

Düssap'ın ailesinin kökenlerinin Ermeni amira sınıfına dayandığını, Düssap ve Vahan Efendi'nin birer amira çocuğu olarak olarak dünyaya geldiklerini ve kendi dönemindeki bir çok Ermeni çocuklarından farklı olarak ayrıcalıklara sahip olduklarına işaret edilir. Anneleri nazlı Vahan'ın genç yaşta eşini kaybettiğini buna karşın Nazlı Vahan'ın son derece bilinçli ve mensubu olduğu sosyal tabakayı çocuklarının eğitiminde nasıl kullanacağının bilincinde bir kadın olduğunun altı çizilir. ${ }^{33}$

Volume 12

Issue 2

A Tribute to Assoc. Prof. Dr. Illknur Mangir Karagöz, April 2020

\footnotetext{
${ }^{32}$ http://www.abrilbooks.com/books/siranush.html (E.T.01.03.2019)

33 Aktokmakyan, agt, ss.54-58.
} 


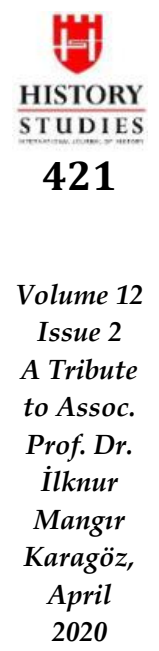

lığa istinaden Sultan'ın Vahan Efendi'yi Roma'ya elçi olarak göndermek istediğini de kaydeden Etker, söz konusu atamanın bilinmeyen nedenlerle gerçekleşmediğini ancak Vahan Efendi'inin, Osmani, Mecidi, altın ve gümüş olmak üzere İmtiyaz ve Girit madalyalarıyla taltif edildiğine de yer vermiştir. Etker Vahan Efendi'nin ayrıca Osmanlı Ticaret Kanununun şerhlerini de yayımladı $\breve{g}$ bilgisine yer vermiştir. ${ }^{35}$

\section{Orhan Vahan'ın Eserleri}

\section{Şerh-ı Kanun-ı Ticaret Adlı Eseri}

Vahan'ın ilk eseri İstanbul'da Takvimhane-i Âmire'de 1278 [1861] y1lında 60 sayfa olarak yayınlanan Şerh-i Kanun-u Ticaret adlı kitabı daha sonra 1882 yılında yeniden Şerh-i Kanun-u Ticaret adıyla bu kez Bekir Efendi Matbaası ve Mahmud Bey Matbaalarında yayınlanmıştır.

\footnotetext{
${ }^{34}$ Terziyan, agm, ss.41-64.

${ }^{35} \mathrm{Agm}, \mathrm{s} .43$.
} 
İkinci baskı olarak Türkçe kaleme alınan bu eserde Vahan Orhan'ın isminin Ohan Vahan olarak yazıldı ğı görülmektedir. ${ }^{36}$

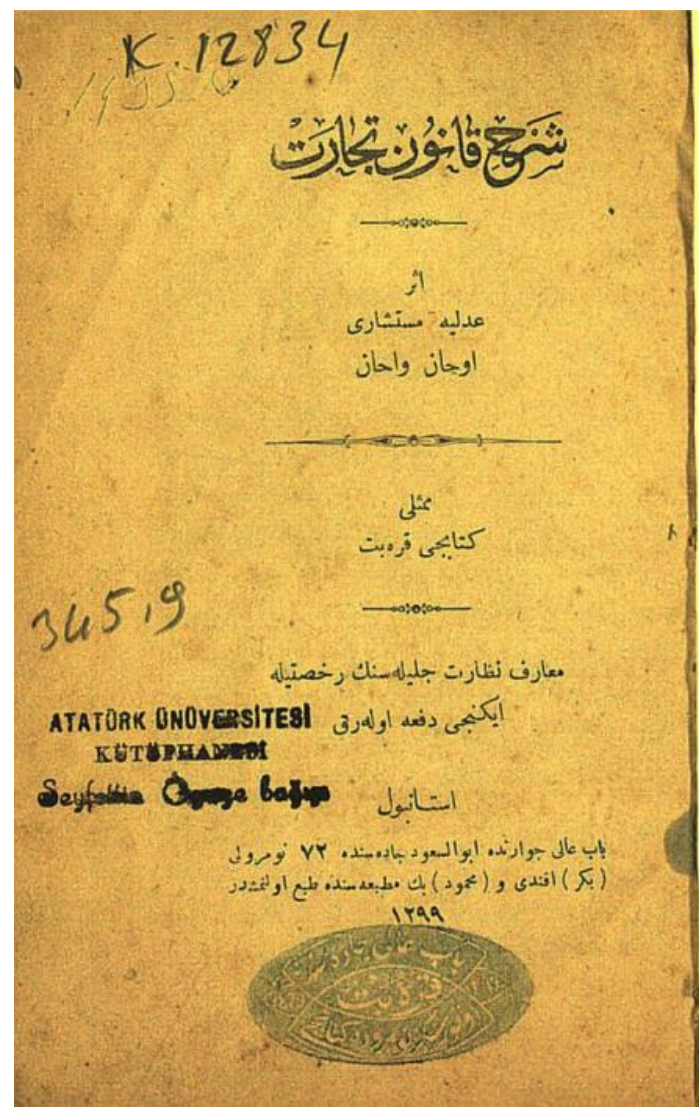

Resim 5: Orhan Vahan'ın Şerh-i Kanun-u Ticaret adlı eserinin

1882 yılındaki ikinci baskıs1. ${ }^{37}$

Vahan'ın bu eseri söz konusu dönemde yürürlüğe giren kanunlar hakkında bilgiler içermesi bakımından son derece önemlidir. Özellikle 1861 'de yürürlüğe giren Ticaret Kanunu'nu ayrıntılarıyla açıklayan bir eser olması nedeniyle dikkat çeker. Vahan eserinin mukaddime bölümünde dönemin Ticaret Nazırı Edhem Paşa'nın Ticaret-i Bahriye Kanunnmaesi'ndeki maddelerinin önemine işaret ederek kendi eserinde bu kanun maddelerinin bire bir şerh edilmeye çalışıldığını kaydetmiştir. Vahan eserinde bazı eksiklikler olsa da genel hatlarıyla poliçe, iflas, ticaret defterlerinin sureti ve tanzimi konularının yanı sıra şirket ve komisyonculuk, poliçe ve iflas hususlarına dair usul ve kanunlar, Ticareti Bahriye Kanunnamesi konuları üzerinde durduğunu belirtir. Vahan hazırlamış olduğu bu eserden daha

\footnotetext{
${ }^{36}$ Vahan, age.

${ }^{37}$ Orhan Vahan, Şerh-i Kanun-u Ticaret, Bekir Efendi ve Mahmud Bey Matbaası, İstanbul, 1882, 2. Baskı.
} 
ziyade Mektebi Şahane'de Ticaret alanında eğitim alan hukuk öğrencilerinin, ticaret zümresi ve ticaret mahkemelerinde görevli memurların ciddi anlamda istifade edeceklerini kaydetmiştir. ${ }^{38}$

\section{Vahan Efendi’nin Ermenice Eserleri}

Vahan Efendi'nin Osmanlıca eserlerinin yanı sira Ermenice eserleri de bulunmaktadır.

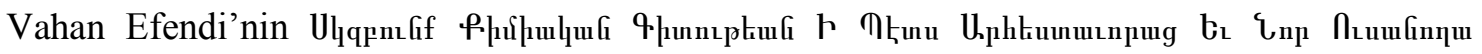
[Isgızpunk Kimiagan Kidutyan] adlı bu eseri 1853 yılında İstanbul'da yayınlanmıştır. ${ }^{39}$ Etker söz konusu eserin Henri-Victor Regnault'nun 1850 yılında Fransızca olarak kaleme almış olduğu Premiers éléments de chimie adlı eserinin Vahan Efendi tarafından Kimya Biliminin Temel Illkeleri adıyla Ermeniceye çevirildiğini ve eserin yayın tarihinden hareketle Vahan Efendi'nin bu eseri Fransa'daki öğrencilik yıllarında çevirdiğini de kaydetmiştir. ${ }^{40} \mathrm{Her}$ ne kadar Vahan bu eseri Ermeniceye çevirmiş olsa da kitapta yer alan 330 Ermenice terimden seçilen örneklerin Türkçe çevirileri ile Ermeni harfli Fransızca karşılıklarının da verilmiş olması önemlidir. ${ }^{41}$ Çalışmanın bir diğer önemli özelliği ise Kimyager Derviş Paşa'nın Usul-i Kimya (1848) adlı eserinden sonra, Türkiye'de yayımlanan ikinci kimya kitabı olmasıdır. Etker'e göre Vahan'ın kitapta zanaatkarlara yönelik bölümlerde Türkçe terimlere yer vermiş olması ise dönemin üretim kültürünü yansıtması açısından önemlidir. ${ }^{42} \mathrm{Bu}$ anlamda Ermenice ilk kimya kitabı olarak da kabul edilen bu eserin önsözünde Vahan Efendi'ninbu eseri kaleme alma nedenine şöyle yer verir;

\footnotetext{
“...Doğada yayılmış bulunan varlıkların niteliklerini incelemek, bunları çeşitli yöntemlerle hazırlamak, türlü türlü zanaatlar icad ederek geliştirmek; işte bu şeyleri bize kimya bilimi öğretir. Dememiz odur ki, bu bilim büyük önem arz etmekte, her sınıftan insanlar ve başta zanaatkarları ilgilendirmektedir. Bu bilimin bize sağladığı yararlar ne kadar büyük, sınırları ne kadar geniş ise de, yüreğimiz sızlayarak itiraf edelim ki, şimdiye kadar onu milletimize tanıtan, milletimizin yaşamına sokan bir Tanrı kulu bulunmamıştır. Elhak, birkaç yıldan beridir çeşit çeşit bilimlere dair birçok kitap günyüzünü gördü, ama kimya bilimiyle ilgili bir kitaba rastgelmedik..."43
}

\footnotetext{
${ }^{38}$ Vahan, age., s.2-4.

${ }^{39}$ Etker, agm, s.41.

${ }^{40}$ Agm, s.44-62.

${ }^{41}$ Agm, s.61, dipnot 67.

${ }^{42}$ Agm, s.63.

${ }^{43}$ Agm, s.41.
} 


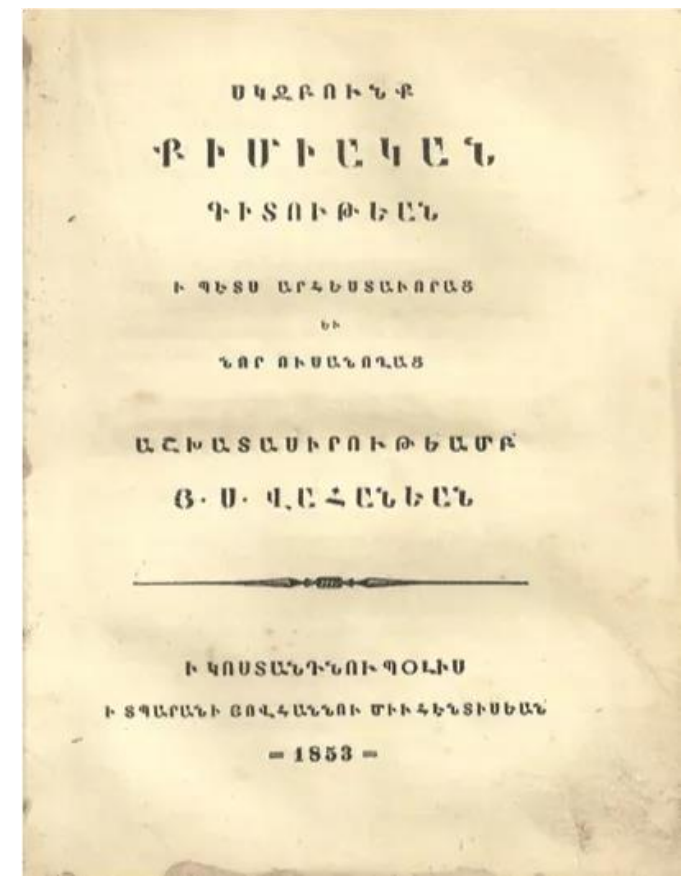

Resim 6: Ermenice ilk kimya kitabi ${ }^{44}$

- Orhan Vahan, Şerh-i Kanun-ı Ticaret, İstanbul 1879 [88].

- Orhan Vahan, Şerh-i Kanun-ı Ticaret, Bekir Efendi ve Mahmud Bey Matbaası, İstanbul 1882, 2. Bask1 [88].

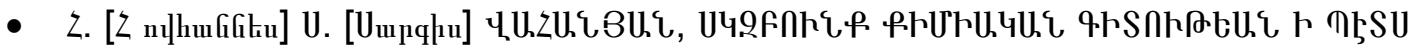

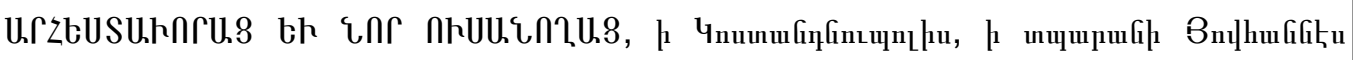
Uhıht, Gunhutwfi, 1853 / [H. [Hovhannes] S. [Sarkis] Vahanyan, Isgızpunk Kimiagan Kidutyan i beds arhestavorats yev usanoğats, i Kostandnupolis, i Dbarani Hovhannes Mühendisyan, 1853] / Zanaatkarlar ve Yeni Öğrenenler için Kimya Biliminin Temel Illkeleri, Hovhannes Mühendisyan Basımevi, İstanbul 1853.

\section{Sonuç}

Sonuç olarak başta tıp, mimari, ekonomi, filoloji ve hukuk olmak üzere bir çok alanda Ermeni entellektüellerinin kaleme aldıkları eserlerden ve benzer çalışmalardan bahsetmek mümkündür. Bu entellektüellerden biri de Orhan Vahan olmuştur. Vahan hem hukuk hem de kimya alanında Osmanlı İmparatorluğu döneminde alanında ilk olarak değerlendirilebilecek olan Şerh-i Kanun-u Ticaret ve Kimya Biliminin Temel Illkeleri adlı çalışmalarıyla ön plana çıkmıştır. Vahan'ın söz konusu eserleri dönemin koşulları göz önünde bulundurulduğunda çağının ilerisinde eserler olarak değerlendirilebilir. Bu yönüyle Osmanlı İmparatorluğu döneminde Ermeni entelijansiyanın pek çok alanda toplumu pozitif yönde etkileyecek bilimsel

\footnotetext{
${ }^{44}$ Tomas Terziyan, "Ermenice İlk Kimya Kitabının Yazarı Hovhannes Sarkis Vahanyan'ın Hikâyesi”, Hyetert,https://hyetert.org/2018/02/01/ermenice-ilk-kimya-kitabinin-yazari-hovhannes-sarkis-vahanyaninhikayesi/(E.T.12.08.2019).
} 
eserler kaleme aldıklarını ve söz konusu eserlerin günümüzde henüz kapsamlı bir şekilde incelenmediğinin de belirtilmesinde yarar vardır. Özellikle üniversitelerin ilgili bölümlerinde söz konusu Ermeni şahsiyetlerinin eserlerinin ve bu eserlerin dönemin entellektüel dünyasındaki yerlerinin kapsamlı bir şekilde ele alnıması yararlı olacaktır.

\section{Kaynakça}

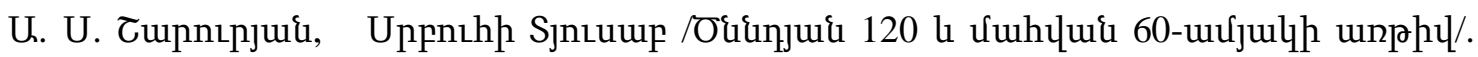
Tuunưu-puquuuppulqui huquntu, 1961, [A. S. Şaruryan, Sirpuhi Düssap /Tzndyan 120 yev Mahvan 60-amyaki ar'tiv, Patma-banasirakan handes], N 3-4 . ss. 166-180.

Armenian Constantinople, Edt: Richard G. Hovannisian, S. Payaslian, Mazda Publishers, USA 2010.

ARTiNiAN, Vartan, Osmanlı Devleti'nde Ermeni Anayasası'nın Doğuşu 1839-1863, Çev: Zülal Kılıç, Aras Yay., İstanbul 2004.

ADAK, Hülya,"Literature (Ottoman Empire)", International Encyclopedia of the First World War,https://encyclopedia.1914-1918online.net/article/literature ottoman empire\#GND 142175331 (E.T.11.12.2018).

AKTOKMAKYAN, Maral, "Sırpuhi Düsap: Ermeni Kadın Edebiyatının Başlangıcı" http://www.arasyayincilik.com/tr/basindan/sirpuhi-dusap-ermeni-kadin-edebiyatininbaslangici/149 (E.T.01.06.2019).

BUDAK, Ali, "Ermeniler'in XIX. Yüzyılda Yeni Bir Hayatın ve Edebiyatın Oluşum Sürecine Katk1ları", Journal of Academic Studies, Y11: 8, Sayi: 30 Ağustos - Ekim 2006, s.137156.

Issue 2

A Tribute

to Assoc.

Prof. Dr.

Illknur

Mangir

Karagöz,

DADYAN, Saro, Osmanlı'da Ermeni Aristokrasisi, Everest Yay., İstanbul 2011.

DEVECI BOZKUŞ, Yıldız, “An Important Armenian Female Writer Prominent in the Ottoman Period: Srpuhi Dussap", http://acikerisim.ybu.edu.tr:8080/xmlui/handle/123456789/550 (E.T.01.06.2019).

DÜSSAP, Sirpuhi, http://www.abrilbooks.com/books/siranush.html (E.T.01.03.2019)

EKMEKÇIOĞLU, Lerna -Melissa Bilal, Bir Adalet Feryad, Aras Yayınevi, İstanbul 2006.

ESEYAN, Markar, 20. Yüzyıla Girerken Ermeni Edebiyatında Modernite, Yeni Burjuvazi ve Sınıfsal Çatışmalar, (İstanbul Bilgi Üniversitesi, Sosyal Bilimler Enstitüsü, Kültürel Çalışmalar Yayınlanmamış Yüksek Lisans Tezi), İstanbul 2010.

ETKER, Şeref, "Vahan Efendi (H.S. Vahanyan) ve Kimya Biliminin Temel İlkeleri”, Osmanlı Bilimi Araştırmaları XIII/2, 2012, ss.41-64.

https://www.facebook.com/SrpouhiDussap/photos/a.683558541701050.1073741827.68349944 $1706960 / 683558401701064 /$ ?type $=3 \&$ theater $($ E.T.11.06.2019)

KIRMIZI, Abdülhamit, "European Educational Backgrounds of Armenian Officials in the Ottoman Empire",Editör: Andreas Schmoller, Middle Eastern Christians and Europe: Historical Legacies and Present Challenges, LIT Verlag, Zurich 2018, ss. 59-78.

KOÇAŞ, M.Sadi,Tarihte Ermeniler ve Türk-Ermeni İlişsileri, Kastaş Yayınları, İstanbul 1990.

KOUYOUMJIAN, Hratch, Ethnic Armenian Civil Servants in the Ottoman Empire in 1909, Great Britain 2015. 
KRIKORIAN, Mesrob K. Armenians in the Service of the Ottoman Empire: 1860-1908, Routledge, London 1977.

OSHAGAN, Vahe, "From Enlightenment to Renaissance: The Armenian Experience", Edt: Richard G. Hovannisian and David N. Myers, Enlightenment and Diaspora, The Armenian and Jewish Cases, Scholor Press, Atlanta, Georgia 1999, ss.145-180.

PANOSSIAN, Razmik, The Armenians, From Kings and Priests to Merchants and Commissars, Columbia University Press, New York 2006.

SÜREYYA, Mehmed,Sicill-i Osmani yahud Tezkere-i Meşahir-i Osmaniye, Matbaa-i amire, İstanbul1311.

ROWE, Victoria,A History Of Armenian Womens Writing: 1880 - 1922, Cambridge Scholars Press,England, 2003.

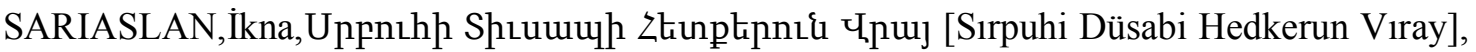
“Sırpuhi Düsap'ın İzleri Üzerinde”, Marmara Gazetesi, 28 Eylül/ 6 Ekim 2006.

"Sırpuhi Düsap ilk feminist Ermeni kadın romancıdır", http://akunq.net/tr/?p=22140 (E.T.03.05.2016).

TERZIYAN, Tomas, "Ermenice ilk kimya kitabının yazarı Hovhannes Sarkis Vahanyan'ın hikâyesi", Hyetert,https://hyetert.org/2018/02/01/ermenice-ilk-kimya-kitabinin-yazarihovhannes-sarkis-vahanyanin-hikayesi/(E.T.12.08.2019).

WASHBURN, George, Robert Koleji'in İlk Müdürü, Cennetin Sonbaharl, Kolej Anıları 18631903, Çev: Z. Bilge Yenice, Atlantis Yayınları, İstanbul 2002.

ZEIDNER, Robert F., "Britain and the Launching of the Armenian Question", International Journal of Middle East Studies, 7(4), 1976, ss.465-483.

ZEKIYAN, Boghos Levon, "Christianity to Modernity", Edt: Edmund Herzig and Marina Kurkchiyan, The Armenians, Past and Present in the Making of National Identity, RoutledgeCurzon, London 2005, ss.41-64. 